\title{
Characterization of genes encoding small heat shock proteins from Bemisia tabaci and expression under thermal stress
}

\author{
Jing Bai ${ }^{1}$, Xiao-Na Liu ${ }^{1}$, Ming-Xing Lu ${ }^{1}$, Yu-Zhou Du ${ }^{\text {Corresp. } 1,2}$ \\ ${ }^{1}$ College of Horticulture and Plant Protection \& Institute of Applied Entomology, Yangzhou University, Yangzhou, China \\ 2 Joint International Research Laboratory of Agriculture and Agri-Product Safety, the Ministry of Education, Yangzhou University, Yangzhou, Jiangsu, China \\ Corresponding Author: Yu-Zhou Du \\ Email address: yzdu@yzu.edu.cn
}

Small heat shock proteins (sHSPs) are probably the most diverse in structure and function among the various super-families of stress proteins, and they play essential roles in various biological processes. The sweet potato whitefly, Bemisia tabaci (Gennadius), feeds in the phloem, transmits several plant viruses, and is an important pest on cotton, vegetables and ornamentals. In this research, we isolated and characterized three $\alpha$ crystallin/sHSP family genes (Bthsp19.5, Bthsp19.2, and Bthsp21.3) from B. tabaci. The three CDNAs encoded proteins of 171,169 and 189 amino acids with calculated molecular weights of 19.5, 19.2 and $21.3 \mathrm{kDa}$ and isoelectric points of $6.1,6.2$ and 6.0 , respectively. The deduced amino acid sequences of the three genes showed strong similarity to sHSPs identified in Hemiptera and Thysanoptera insects species. All three sHSPs genes from $B$. tabaci lacked introns. Quantitative Real-time PCR analyses revealed that the three BtsHSPs genes were significantly up-regulated in $B$. tabaci adults and pupae during high temperature stress $\left(39,41,43\right.$, and $\left.45^{\circ} \mathrm{C}\right)$ but not in response to cold temperature stress $\left(-6,-8,-10\right.$, and $\left.-12^{\circ} \mathrm{C}\right)$. The expression levels of $B$ thsp19.2 and Bthsp21.3 in pupae was higher than adults in response to heat stress, while the expression level of Bthsp19.5 in adults was higher than pupae. In conclusion, this research results show that the sHSP genes of Bemisia tabaci had shown differential expression changes under thermal stress. 
1 Characterization of genes encoding small heat shock proteins from Bemisia tabaci and expression under thermal stress

4 Jing Bai ${ }^{1}$, Xiao-Na Liu ${ }^{1}$, Ming-Xing $\mathrm{Lu}^{1}$ and $\mathrm{Yu}-\mathrm{Zhou} \mathrm{Du}^{1,2, *}$

$6{ }^{1}$ College of Horticulture and Plant Protection \& Institute of Applied Entomology, Yangzhou 7 University, Yangzhou 225009, China

8 2Joint International Research Laboratory of Agriculture and Agri-Product Safety, the Ministry of 9 Education, Yangzhou University, Yangzhou, China

*Correspondence author: Yu-Zhou Du,

Email Address: yzdu@yzu.edu.cn

\section{Abstract}

17 Small heat shock proteins (sHSPs) are probably the most diverse in structure and function among the various super-families of stress proteins, and they play essential roles in various biological processes. The sweet potato whitefly, Bemisia tabaci (Gennadius), feeds in the phloem, transmits several plant viruses, and is an important pest on cotton, vegetables and ornamentals. In this research, we isolated and characterized three $\alpha$-crystallin/sHSP family genes (Bthsp 19.5, 
23189 amino acids with calculated molecular weights of $19.5,19.2$ and $21.3 \mathrm{kDa}$ and isoelectric 24 points of $6.1,6.2$ and 6.0, respectively. The deduced amino acid sequences of the three genes 25 showed strong similarity to sHSPs identified in Hemiptera and Thysanoptera insects species. All three sHSPs genes from B. tabaci lacked introns. Quantitative Real-time PCR analyses revealed that the three BtsHSPs genes were significantly up-regulated in B. tabaci adults and pupae during high temperature stress $\left(39,41,43\right.$, and $\left.45^{\circ} \mathrm{C}\right)$ but not in response to cold temperature stress $(-6$, 8, -10 , and $\left.-12^{\circ} \mathrm{C}\right)$. The expression levels of Bthsp19.2 and Bthsp21.3 in pupae was higher than adults in response to heat stress, while the expression level of Bthsp19.5 in adults was higher than pupae. In conclusion, this research results show that the sHSP genes of Bemisia tabaci had shown differential expression changes under thermal stress.

\section{Introduction}

Heat shock proteins comprise a group of highly-conserved proteins that are widely found in prokaryotes and eukaryotes. At present, heat shock proteins can be divided into HSP100, HSP90, HSP70, HSP60, HSP40 and small heat shock proteins (sHSPs) according to their molecular weight and homology (Kim et al., 1998; Sǿrensen et al., 2003). sHSPs are the least conserved family of all heat shock proteins and were first identified as a set of low molecular proteins $(15-43 \mathrm{kDa})$ induced after heat shock in Drosophila melanogaster (Tissières et al., 1974). sHSPs 
42 exhibit more diversity in sequence, structure, size, and function compared to other types of HSPs

43 (De Jong et al., 1998; Franck et al., 2004). They are a superfamily of proteins that contain an $\alpha-$

44 crystallin domain and variable N- and C-terminal extensions (Stromer et al., 2004). Because the members of this protein family are very dynamic and heterogeneous, information on structure and function is lacking (Haslbeck et al., 2005; Horwitz, 2003). Some sHSPs act as molecular chaperones to block the aggregation of unfolded proteins and have properties of protecting cell under stress environment (Garrido et al., 2012). sHSPs also play some important roles in apoptosis and autophagy, actin and intermediate filament kinetics, cytoskeletal tissue and membrane fluidity in addition to the stress response (Haslbeck, 2002; Quinlan, 2002; Tsvetkova et al., 2002; Sun \& MacRae, 2005). Since insects have a strong ability to adapt to a variety of habitats, it is important to understand the roles of sHSP in invertebrates. According to previous studies, sHSPs play important roles in adaptation to hot/cold stress, metamorphosis, normal development, diapause and the immune response (Parsell \& Lindquist, 1993; Jakob \& Buchner, 1994; Feder \& Hofmann, 1999; Hayward et al., 2005; Song et al., 2006; Huang \& Kang, 2007;

Rinehart et al., 2007; Gu et al., 2012; Lu et al., 2014; Pan et al., 2017). Hemiptera and is an important pest of cotton, vegetables and bedding plants. It causes damage by ingesting phloem, transmitting plant viruses, and also by secreting honeydew, which can decrease photosynthesis. B. tabaci has caused large economic losses in agricultural production worldwide (De Barro et al., 2011). As one of the 100 most invasive organisms in the world, the 
62

63

64

65

66

67

68

69

occurrence of B. tabaci is also very serious in China. In particular, the Mediterranean (MED) or Q biotype of B. tabaci has been rapidly expanding and causing harm in China with increased fecundity, a shorter developmental period and stronger resistance to stress since its first discovery in 2005 (Chu et al., 2005, Xu et al., 2006). Therefore, it is very necessary to conduct relevant research on this insect.

It is well known that temperature is one of the important factors affecting the survival and growth of insects. Many HSP genes including sHSP genes related to temperature adaption and stress have been screened and identified in different insect species (Hoffmann et al., 2003; McMillan et al., 2005; Somero, 2005; Nann et al., 2006; Pan et al., 2017; Pan et al., 2018; Qin et al., 2018; Yu et al., 2018; Xiong et al., 2018). Although the sHSP of B. tabaci (heat shock protein 20, hsp20) has been studied before, there are still some deficiencies in this research scopes. So in this paper, three sHSP genes were cloned and analyzed, and expression patterns were analyzed in detail, further enriching our knowledge of B. tabaci HSPs.

\section{Materials \& Methods}

\section{Insects}

The B. tabaci populations used in this study were collected from vegetable farms in Yangzhou 79 (Jiangsu China). MED cryptic species was determined by using mtDNA COI gene. Insects were reared in environmental chambers on tomato plants at $26 \pm 1{ }^{\circ} \mathrm{C}$, with a $16 \mathrm{~L}: 8 \mathrm{D}$ photoperiod 
81 and $60 \%$ relative humidity.

82

\section{Temperature Treatments}

84 Cohorts of 120 B. tabaci adults and pupae were collected respectively, placed in glass tubes, and exposed to each temperature treatments $\left(-12,-10,-8,-6,39,41,43\right.$, and $\left.45^{\circ} \mathrm{C}\right)$ for $1 \mathrm{~h}$ in a constant-temperature subzero incubator (DC-3010; Jiangnan Equipment). Treated adults and pupae were allowed to recover at $25^{\circ} \mathrm{C}$ for $1 \mathrm{~h}$ and were then frozen in liquid nitrogen and stored at $-80^{\circ} \mathrm{C}$. Adults and pupae exposed to $26^{\circ} \mathrm{C}$ were included as a control. Each treatment included

89 four biological replications $(\mathrm{N}=4)$.

91 Total RNA, Cloning and RACE

92 Total RNA was extracted from B. tabaci adults and pupae using the SV Total RNA Isolation and

93 Purification Kit (Promega). The integrity, purity and concentration of RNA were examined using $941 \%$ agarose gel electrophoresis and spectrophotometry at 260 and $280 \mathrm{~nm}$ (Eppendorf

95 BioPhotometer plus). RNA samples were stored at $-80^{\circ} \mathrm{C}$ until needed. cDNA was synthesized 96 using an oligo(dT) $)_{18}$ primer (TaKaRa), and full-length cDNAs of genes encoding sHSPs were 97 obtained by 5'-and 3'-RACE (SMART RACE, Clontech) using the primers shown in Table 1. 98 Full-length sequences were confirmed by RACE 5' cDNA. 


\section{Characterization Genome of B. tabaci}

101 The genomic DNA of B. tabaci was extracted as described previously(Xu et al., 2014). Pairs of 102 specific primers (Table 1) were designed to amplify genomic fragments from the three BtsHSP 103 genes. Products were purified using a gel extraction kit (Axygen, USA), cloned into PGEM-T 104 Easy vector (Promega, USA), and transformed into competent Escherichia coli DH5 $\alpha$ cells for 105 sequencing.

106

107

108

109

110

111

112

113

Open reading frames (ORFs) were identified using ORF Finder software (http://www.ncbi.nlm.nih.gov/gorf/gorf.html). The deduced amino acid sequences were aligned using ClustalX software (version 1.83) (Thompson et al., 2002). Sequence analysis tools of the ExPASy Molecular Biology Server of the Swiss Institute of Bioinformatics, including Translate, Compute $\mathrm{pI} / \mathrm{MW}$, and Blast, were used to analyze the deduced small heat shock protein sequences. Amino acid sequences were used to estimate phylogeny using neighbor-joining, minimum evolution, maximum likelihood, and maximum parsimony methods. Phylogenetic trees were constructed with 1,000 bootstrap replicates using MEGA (version 7.0) (Kumar et al., 2016).

\section{Quantitative Real-Time PCR (qRT PCR)}

Total RNA was extracted using the SV Total RNA isolation system (Promega Z3100). The integrity of RNA in all samples was verified by comparing ribosomal RNA bands in ethidium 
118 bromide-stained gels. RNA purity was evaluated by spectrophotometry (Eppendorf

119 BioPhotometer plus) at 260 and $280 \mathrm{~nm}$. Following qPCR, the homogeneity of PCR products

120 was confirmed by melting curve analysis, which was read every $5 \mathrm{~s}$ per $0.5^{\circ} \mathrm{C}$ increment from 65

121 to $95^{\circ} \mathrm{C}$. Each reaction was performed in triplicate, and the means of three independent replicates

122 were calculated. Quantitative real-time PCR (qPCR) reactions were performed in $20 \mu$ total

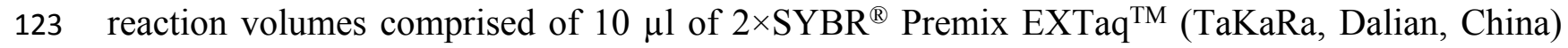

124 master mix, $1 \mu$ of each gene specific primer (Table 1), and $2 \mu$ of cDNA templates. It was

125 carried out that reactions on a CFX-Connect real-time PCR system (Bio-Rad) using the

126 following conditions: $3 \mathrm{~min}$ at $95^{\circ} \mathrm{C}, 40$ cycles of denaturation at $95^{\circ} \mathrm{C}$ for $30 \mathrm{~s}$, and annealing

127 (30 s) at the Tm for each gene. The quantity of BtsHSP mRNA was calculated using the $2^{-\Delta \Delta \mathrm{Ct}}$

128 method and normalized to the abundance of the gene encoding elongation factor $1 \alpha(E F-1 \alpha)$.

\section{Data Analysis}

131 We used Levene's test to evaluate the homogeneity of variances among different groups.

132 Significant differences between treatments were identified with either an LSD test (homogeneity

133 of variances) or Dunnett's $\mathrm{C}$ test (nonhomogeneous) for multiple comparisons. The data were

134 analyzed using SPSS 16.0 software (Pallant, 2005) and represented as means \pm SE (standard 135 error). 
137 Results

\section{Sequence Analysis of B. tabaci sHSPs}

139 Three B. tabaci sHSPs were identified and designated Bthsp19.5, Bthsp19.2 and Bthsp21.3; these 140 were deposited in GenBank as accession nos. MF114301, MF114302 and MF114303, 141 respectively. Comparing with the databases of GenBank and PROSITE, the three deduced 142 proteins had high similarity to sHSP family and contained the typical $\alpha$-crystalline domain at the 143 following locations: BtHSP19.5, 46-155 aa (Fig. S1A); BtHSP19.2, 45-154 aa (Fig. S1B); and 144 BtHSP21.3, 45-154 aa (Fig. S1C). The three full-length cDNAs were 1225, 1107, and 1209 bp, 145 respectively. The deduced protein products contained 171, 169 and 189 amino acids with 146 isoelectric points of 6.1, 6.2 and 6.0, respectively. Each 3' UTR contained a polyadenylation 147 signal (AATAAA) located 13 (Bthsp19.5), 16 (Bthsp19.2), and 32 bp (Bthsp21.3) upstream of 148 the poly(A) tract. Multiple sequence alignment (Fig. 1) revealed high identity between the three 149 BtHSPs.

Phylogenetic analysis of $B$. tabaci sHSPs

The three sHSPs' deduced amino acid sequences were compared with orthologous proteins that reported in other insects (Table 2). The ClustalX software revealed B. tabaci HSP19.5, HSP19.2 and HSP21.3 showed high sequence identity with HSP20 in B. tabaci and Frankliniella occidentalis (Fig. 1). The MEGA revealed four phylogenetic trees (neighbor-joining, minimum 
156

157

158

159

160

161

162

163

164

165

166

167

evolution, maximum likelihood, and maximum parsimony methods) with a similar trend, so we choose neighbor-joining phylogenetic tree as the representative and the three $B$. tabaci sHSPs were grouped together in a well-supported cluster (Fig. 2). Furthermore, the three sHSPs of $B$. tabaci also are divided into groups of Hemiptera (Laodelphax striatella) and Thysanoptera (Frankliniella occidentalis) insects, and are far from Bemisia tabaci HSP20 which have reported in the past.

\section{Genomic Structure of Three Genes Encoding B. tabaci sHSPs}

The length of genomic DNA sequences of the three B. tabaci sHSPs varied as follows: $1225 \mathrm{bp}$ for Bthsp19.5 (GenBank accession no. MF114301); 1107 bp for Bthsp19.2 (MF114302); and 1209 bp for Bthsp21.3 (MF114303). The cDNA is aligned with the genomic DNA sequence and the intron splicing chain nucleotide sequence GT-AG rules were used to find that all the three $B$. tabaci sHSP genes (Bthsp19.5, Bthsp19.2 and Bthsp21.3) lacked introns, which is also the case for Bmhsp20.4 and Lmhsp20.7 from Bombyx mori and Locusta migratoria, respectively (Fig. 3). However, some shsps do contain introns; examples include Cshsp21.4 and Bmhsp21.4, which contain one and two introns, respectively (Fig. 3).

\section{Expression of BtsHSPs in Response to Temperature Stress}

The RT-PCR was used to study the expression profiles of the three shsps in the MED cryptic 
175

176

177

178

179

180

181

182

183

184

185

186

187

188

189

190

191

192

193

194

species of B. tabaci. Melting curve analysis revealed the presence of a single, sharply defined peak for Bthsp19.5 $\left(\mathrm{R}^{2}=0.884\right)$ Bthsp19.2 $\left(\mathrm{R}^{2}=0.938\right)$ and Bthsp21.3 $\left(\mathrm{R}^{2}=0.992\right)$. The relative mRNA levels of the three shsps were compared at $-12,-10,-8,-6,26,39,41,43$ and $45^{\circ} \mathrm{C}$. The expression profiles for the three $B$. tabaci sHSP genes were very similar at each of the selected temperatures (Fig. 4). In both adult and pupa forms of B. tabaci, Bthsp19.5 $\left(F_{17,44}=223.837\right.$, $P<0.05)$, Bthsp19.2 $\left(F_{17,48}=114.250, P<0.05\right)$ and Bthsp21.3 $\left(F_{17,45}=82.582, P<0.05\right)$ were significantly induced in response to heat stress $\left(39\right.$ to $\left.45^{\circ} \mathrm{C}\right)$, whereas expression at cold temperatures $\left(-6\right.$ to $\left.-12^{\circ} \mathrm{C}\right)$ was not significantly different from the control $\left(26^{\circ} \mathrm{C}\right)$. We also observed differences in shsps expression in adult and pupa forms of $B$. tabaci exposed to heat stress. The expression levels of Bthsp19.2 and Bthsp21.3 were significantly higher in pupae than adults, and expression was highest at $41^{\circ} \mathrm{C}$ (Fig. 4B,C). In contrast, the expression of Bthsp19.5 was greatest in adults exposed to $43^{\circ} \mathrm{C}$ (Fig. 4A).

\section{Discussion}

sHSPs are the least conserved family of heat shock proteins. Although the nucleotide sequence and size of sHSPs are diverse, the majority retain common characteristics (Franck et al., 2004; Haslbeck et al., 2005). Increasing numbers of studies have found that sHSPs are closely linked to many important functions in insects, such as regulating growth and reproduction, which enhances the ability of insects to adapt to environmental stress, and they are also closely related to insect dormancy and diapause (Lu et al., 2015). 
In this study, we identified three new sHSP genes from the MED cryptic species $B$. tabaci:

196

197

198

199

200

201

202

203

204

205

206

207

208

209

210

211

212

213

214

Bthsp19.5, Bthsp19.2 and Bthsp21.3. The predicted amino acid sequences of Bthsp19.5, Bthsp19.2 and Bthsp21.3 show high sequence similarity to hsp20 from the MED cryptic species

B. tabaci and Trialeurodes vaporariorum, especially in the $\alpha$-crystallin protein. Phylogenetic analysis placed the three BtsHSPs proteins in the same cluster (Fig. 3), which comprises a large group containing the Hemiptera species, Laodelphax striatella, and Thysanoptera species, Frankliniella occidentalis. The previously reported $B$. tabaci HSP20 proteins (B, Q, ZHJ-1, ZHJ2) and HSP20 orthologs from other Hemipteran insects (Trialeurodes vaporariorum and Lygus hesperus) grouped separately (Yu and Wan, 2009; Yu et al., 2012a; Yu et al., 2012b; Hull et al., 2013), indicating that the three BtsHSPs identified in this study belong to the new MED cryptic species of B. tabaci. Of course, it remains to be studied further that whether there are other sHSPs in the body of B. tabaci.

Previous studies have established a negative conjunction between gene expression and intron size; In other words, genes with short or missing introns are expressed more highly than genes with long or multiple introns (Comeron, 2004). Genes of sHSP have been classified into two types: orthogonal and species-specific based on chromosomal location and intron number ( $\mathrm{Li}$ et al., 2009). Our results indicate that Bthsp19.5, Bthsp19.2 and Bthsp21.3 are species-specific forms of sHSP that lack introns.

Prior studies have established that HSPs contribute to temperature tolerance (Sørensen et al., 2003; Queitsch et al., 2002), and our study is no exception. The expression levels of Bthsp19.5, 
215 Bthsp19.2 and Bthsp21.3 were significantly up-regulated during high temperature stress, 216 indicating that sHSPs function in heat tolerance of the MED cryptic species $B$. tabaci. This result 217 is associated with Gerhring \& Wehner (1995) HSPs involved in multiple physiological processes, 218 one of the most well-known functions is to improve the heat tolerance of insects and protect 219 insects from heat damage and lethal damage. Our findings are consistent with those obtained for Bthsp20, which is also induced by heat stress ( $Y u$ et al., 2012). Although the role of sHSPs in modulating heat resistance is documented for insects, the response to cold stress is less obvious.

For example, hsp21.4 (B. mori), hsp20 and hsp21.4 (S. litura) and hsp21.4 and hsp21.7b (C. suppressalis) are not sensitive to low temperature stress (Li et al., 2009; Shen et al., 2011; Lu et al., 2014). Similarly, our results indicated that the expression levels of Bthsp19.5, Bthsp19.2 and Bthsp21.3 were not modulated by cold shock (Fig. 4). It is important to mention that control of HSP expression is critical in maintaining the cost/benefit ratio of these proteins since overexpression can cause deleterious effects (Krebs \& Feder, 1998; Sørensen et al., 2003). Further indicating that insects may not have cross resistance between heat and cold adaptation (Huang et al., 2007). sHSPs also play an important role in insect development (Concha et al., 2012; Shen et al., 2011; Takahashi et al., 2010). For example, the expression of l(2)efl, which encodes a sHSP, was

232 highest in third instar larvae of Drosophila melanogaster (Kurzik-Dumke \& Lohmann, 1995). 233 However, in Lucilia cuprina, expression of hsp24 was lowest in third instar larvae (Concha et al., 234 2012). Previous studies on HSPs in B. tabaci were primarily focused on adults (Yu et al., 2012a; 
235 Yu et al., 2012b; Yu \& Wan, 2009; Díaz et al., 2015). In the present study, we observed 236 differential expression of Btshsps in adult and pupa forms of B. tabaci; for example, expression 237 of Bthsp19.2 and Bthsp21.3 was significantly higher in pupae than adults (Fig. 4B, C). In 238 contrast, Bthsp19.5 expression was significantly higher in adults than pupae and showed no 239 significant difference in transcription during high temperature stress. Thus, Bthsp19.2 and 240 Bthsp21.3 function during the pupal stage and Bthsp19.5 expression is important in adults; 241 furthermore, Bthsp19.5 may have a role in pupae exposed to cold stress (Fig. 4A). Previous 242 studies suggested a link between HSP expression and insect developmental stage. For example, 243 the relative expression levels of three HSP genes of 2 nd instar nymphs at each temperature were 244 lower than those of third instar nymphs and female adults in Phenacoccus solenopsis (Chen \& $245 \mathrm{Lu}, 2014$ ). In another research, the expression of Sihsp20.6 and Sihsp19.6 was highest in eggs of 246 Sesamia inferens, whereas the expression of Sihsp21.4 was highest in adults (Sun et al., 2014). ecological levels is important for predicting epidemiological spread and intrusiveness. Further research is needed to elucidate the role of sHSPs in insect behavior and development and to 250 determine their relevance to invasiveness. These studies will help to uncover the basic mechanisms of physiological that contribute to insect survival and will improve our capability to 252 carry out more effective control measures finally. 
255

256

257

258

259

260

261

262

263

264

265

266

267

268

269

270

271

272

273

274

275

276

277

278

279

280

281

282

We sincerely thank Dr. Carol L. Bender for editing English and helpful comments on the manuscript.

\section{References}

Chen F, Lu YY. 2014. Expression analysis of heat shock protein genes in Phenacoccus solenopsis (Hemiptera: Pseudococcidae) under temperature stress. Acta Entomologica Sinica 57(11):1253-1264. (in Chinese)

Chu D, Zhang YJ, Cong B, Xu BY, Wu QJ. 2005. Identification for Yunnan Q biotype. Bulletin of Entomology 42(1):54-56. (in Chinese)

Comeron JM. 2004. Selective and mutational patterns associated with gene expression in humans: Influences on synonymous composition and intron presence. Genetics 167(3):1293-1304.

Concha C, Edman RM, Belikoff EJ, Schiemann AH, Carey B, Scott MJ. 2012. Organization and expression of the Australian sheep blowfly (Lucilia cuprina) hsp23, hsp24, hsp70 and hsp83 genes. Insect Molecular Biology 21(2):169-180.

De Barro PJ, Liu SS, Boykin LM, Dinsdale AB. 2011. Bemisia tabaci: a statement of species ststus. Annual Review of Entomology 56:1-19.

De Jong WW, Caspers GJ, Leunissen JA. 1998. Genealogy of the $\alpha$-crystallin-small heat-shock protein superfamily. International Journal of Biological Macromolecules 22(3-4):151-162.

Díaz F, Orobio RF, Chavarriaga P, Toro-Perea N. 2015. Differential expression patterns among heat-shock protein genes and thermal responses in the whitefly Bemisia tabaci (MEAM 1). Journal of Thermal Biology 52:199-207.

Feder ME, Hofmann GE. 1999. Heat shock proteins, molecular chaperones, and the stress response: Evolutionary and ecological physiology. Annual Review of Physiology 61:243-282.

Franck E, Madsen O, van Rheede T, Ricard G, Huynen MA, de Jong WW. 2004. Evolutionary diversity of vertebrate small heat shock proteins. Journal of Molecular Evolution 59(6):792-805.

Garrido C, Paul C, Seigneuric R, Kampinga HH. 2012. The small heat shock proteins family: Thelong forgotten chaperones. The International Journal of Biochemistry \& Cell Biology 44(10):1588-1592.

Gehring WJ, Werner R. 1995. Heat shock protein synthesis and thermotolerance in Cataglyphis, an ant from the Sahara desert. Proceedings of the National Academy of Science of the United States of America 92(7):2994-2998. 
Gu J, Huang LX, Shen Y, Huang LH, Feng QL. 2012. Hsp70 and small Hsps are the major heat shock protein members involved in mid gut metamorphosis in the common cutworm, Spodoptera litura. Insect Molecular Biology 21(5):535-543.

Haslbeck M. 2002. sHsps and their role in the chaperone network. Cellular and Molecular Life Sciences 59(10):51-60.

Haslbeck M, Franzmann T, Weinfurtner D, Buchner J. 2005. Some like it hot: The structure and function of small heat-shock proteins. Nature Structural \& Molecular Biology 12(10):842-846.

Hayward SAL, Pavlidesb SC, Tammariellob SP, Rineharta JP, Denlinger DL. 2005. Temporal expression patterns of diapause associated genes in flesh fly pupae from the onset of diapause through post-diapause quiescence. Journal of Insect Physiology 51(6):631-640.

Hoffmann AA, Sørensen GJ, Loeschcke V. 2003. Adaptation of Drosophila to temperature extremes: bringing together quantitative and molecular approaches. Journal of Thermal Biology 28(3):175-216.

Horwitz J. 2003. Alpha-crystallin. Experimental Eye Research 76(2):145-153.

Huang LH, Chen B, Kang L. 2007. Impact of mild temperature hardening on thermotolerance, fecundity, and Hsp gene expression in Liriomyza huidobrensis. Journal of Insect Physiology 53(12):1199-1205.

Huang LH, Kang L. 2007. Cloning and inter-specific altered expression of heat shock protein genes in two leaf miner species in response to thermal stress. Insect Molecular Biology 16(4):491-500.

Hull JJ, Geib SM, Fabrick JA, Brent CS. 2013. Sequencing and de novo assembly of the western tarnished plant bug (Lygus hesperus) transcriptome. PLoS One 8(1):e55105.

Intergovernmental Panel on Climate Change. 2007. IPCC fourth assessment report, climate change 2007. Working group I report. The physical science basis. Cambridge: Cambridge University Press, 747 - 845.

Jakob U, Buchner J. 1994. Assisting spontaneity: The role of Hsp90 and small Hsps as molecular chaperones. Trends Biochemical of Sciences 19(5):205-211.

Kim KK, Kim R, Kim S. 1998. Crystal structure of small heat-shock protein. Nature 394(6693):595-599.

Krebs RA, Feder ME. 1998. Hsp70 and larval thermotolerance in Drosophila melanogaster: How much is enough and when is more too much? Journal of Insect Physiology 44(11):1091-1101.

Kumar S, Stecher G, Tamura K. 2016. MEGA7: Molecular Evolutionary Genetics Analysis version 7.0 for bigger datasets. Molecular Biology and Evolution 33(7):1870-1874.

Kurzik-Dumke U, Lohmann E. 1995. Sequence of the new Drosophila melanogaster small heat-shockrelated gene, lethal (2) essential for life [ $l$ (2) efl], at locus 59F4, 5. Gene 154(2):171-175. 
Li RM, Xie W, Wang SL, Wu QJ, Yang NN, Yang X, Pan HP, Zhou XM, Bai LY, Xu BY, Zhou XG, Zhang YJ. 2013. Reference gene selection for qRT-PCR analysis in the sweet potato whitefly, Bemisia tabaci (Hemiptera: Aleyrodidae). PLoS One 8:e53006.

Li ZW, Li X, Yu QY, Xiang ZH, Kishino H, Zhang Z. 2009. The small heat shock protein (sHSP) genes in the silk worm, Bombyx mori, and comparative analysis with other insect sHSP genes. BMC Evolutionary Biology 9:215.

Lu MX, Hua J, Cui YD, Du YZ. 2014. Five small heat shock protein genes from Chilo suppressalis: Characteristics of gene, genomic organization, structural analysis, and transcription profiles. Cell Stress Chaperones 19(1):91-104.

Lu MX, Xu J, Du YZ. 2015. Progress in research on insect small heat shock proteins. Journal of Applied Entomology 52(6):1326-1332. (in Chinese)

Mcmillan DM, Fearnley SL, Rank NE, Dahlhoff EP. 2005. Natural temperature variation affects larval survival, development and Hsp70 expression in a leaf beetle. Functional Ecology 19(5):844-852.

Nann AF, Myriam H, Patricia MS. 2006. Intraspecific variation in thermal tolerance and heat shock protein gene expression in common killifish, Fundulus heteroclitus. Journal of Experimental Biology 209(15):2859-2872.

Pallant J. 2005. SPSS Survival Manual: A Step by Step Guide to Data Analysis using SPSS for Windows (Version 12). Maidenhead: Open University Press.

Pan DD, Lu MX, Li QY, Du YZ. 2017. Characteristics and expression of genes encoding two small heat shock protein genes lacking introns from Chilo suppressalis. Cell Stress Chaperones 23(1):1-10.

Pan DD, Cao SS, Lu MX, Hang SB, Du YZ. 2018. Genes encoding heat shock proteins in the endoparasitoid wasp, Cotesia chilonis, and their expression in response to temperatures. Journal of Integrative Agriculture 17(5): 1012-1022.

Parsell DA, Lindquist S. 1993. The function of heat shock proteins in stress tolerance: Degradation and reactivation of damaged proteins. Annual Review of Genetics 27:437-496.

Qin J, Gao P, Zhang XX, Lu MX, Du YZ. 2018. Characterization of two novel heat shock protein 70s and their transcriptional expression patterns in response to thermal stress in adult of Frankliniella occidentalis (Thysanoptera: Thripidae). Journal of Integrative Agriculture 17(5):1023-1031.

Queitsch C, Sangster TA, Lindquist S. 2002. Hsp90 as a capacitor of phenotypic variation. Nature 417(6889):618-624.

Quinlan R. 2002. Cytoskeletal competence requires protein chaperones. Progress in Molecular and Subcellular Biology 28:219-234. 
Rinehart JP, Li AQ, Yocum GD, Robich RM, Hayward SAL, Denlinger DL. 2007. Up-regulation of heat shock proteins is essential for cold survival during insect diapause. Proceedings of the National Academy of Science of the United States of America 104(27):11130-11137.

Shen Y, Gu J, Huang LH, Zheng SC, Liu L, Xu WH. Feng QL, Kang L. 2011. Cloning and expression analysis of six small heat shock protein genes in the common cutworm, Spodoptera litura. Journal of Insect Physiology 57(7):908-914.

Somero GN. 2005. Linking biogeography to physiology: evolutionary and acclamatory adjustments of thermal limits. Front Zool 2(1):1-9.

Song KH, Jung SJ, Seo YR, Kang SW, Han SS. 2006. Identification of up-regulated proteins in the hemolymph of immunized Bombyx mori larvae. Comparative Biochemistry Physiology Part D Genomics Proteomics 1(2):260-266.

Sórensen JG, Kristensen TN, Loeschcke V. 2003. The evolutionary and ecological role of heat shock proteins. Ecology Letters 6(11):1025-1037.

Stromer T, Fischer E, Richter K, Haslbeck M, Buchner J. 2004. Analysis of the regulation of themolecular chaperone Hsp26 by temperature-induced dissociation: The N-terminal domail is important for oligomer assembly and the binding of unfolding proteins. Journal of Biological Chemistry 279(12):11222-11228.

Sun M, Lu MX, Tang XT, Du YZ. 2014. Characterization and Expression of Genes Encoding Three Small Heat Shock Proteins in Sesamia inferens (Lepidoptera: Noctuidae). International Journal of Molecular Sciences 15(12):23196-23211.

Sun Y, MacRae TH. 2005. Small heat shock proteins: Molecular structure and chaperone function. Cellular and Molecular Life Sciences 62(21):2460-2476.

Takahashi KH, Rako L, Takano-Shimizu T, Hoffmann AA, Lee SF. 2010. Effects of small Hsp genes on developmental stability and micro-environmental canalization. BMC Evolutionary Biology 10(1):284.

Thompson JD, Gibson TJ, Higgins DG. 2002. Multiple sequence alignment using ClustalW and ClustalX. Current Protocols in Bioinformatics Chapter 2:Unit 2.3.

Tissières A, Mitchell HK, Tracy UM. 1974. Protein synthesis in salivary glands of Drosophila melanogaster: Relation to chromosome puffs. Journal of Molecular Biology 84(3):389-398.

Tsvetkova NM, Horvath I, Torok Z, Wolkers WF, Balogi Z, Shigapova N. Crowe LM, Tablin F, Vierling E, Crowe JH, Vigh L. 2002. Small heat shock proteins regulate membrane lipid polymorphism. Proceedings of the National Academy of Science of the United States of America 99(21):13504-13509.

PeerJ reviewing PDF | (2018:12:33852:1:2:NEW 17 Apr 2019) 
375

376

377

378

379

380

381

382

383

384

385

386

387

388

389

390

391

Xiong WF, Xie J, Wei LT, Zhang SS, Song XW, Gao SS, Li B. 2018. Transcriptome analysis of hsp18.3 functions and regulatory systems using RNA-sequencing in the red flour beetle, Tribolium castaneum. Journal of Integrative Agriculture 17(5):1040-1056.

Xu J, Wang WL, Liu SS. 2006. The occurrence of Bemisia tabaci in partial Zhejiang Province. Plant Protection 32:121. (in Chinese)

Xu LL, Cai L, Shen WJ, Du YZ. 2014. Biotypes and phylogenetic analysis of Bemisia tabaci (Hemiptera: Aleyrodidae) in China. Journal of Applied Ecology 25(4):1137-1144. (in Chinese)

Yu H, Wan FH. 2009. Cloning and expression of heat shock protein genes in two whitefly species in response to thermal stress. Journal of Applied Entomology 133(8):602-614.

Yu H, Wan FH, Guo JY. 2012a. Different thermal tolerance and Hsp gene expression in invasive and indigenous sibling species of Bemisia tabaci. Biological Invasions 14(8):1587-1595.

Yu H, Wan FH, Guo JY. 2012b. cDNA Cloning of Heat Shock Protein Genes and Their Expression in an Indigenous Cryptic Species of the Whitefly Bemisia tabaci Complex from China. Journal of Integrative Agriculture 11(2):293-302.

Yu TY, Lu MX, Cui YD. 2018. Characterization of T-complex polypeptide 1 (TCP-1) from the Chilo suppressalis HSP60 family and its expression in response to temperature stress. Journal of Integrative Agriculture 17(5):1032-1039. 


\section{Table 1 (on next page)}

Primer sequences used in RACE and real-time quantitative PCR 
1 TABLE 1 Primer sequences used in RACE and real-time quantitative PCR

\begin{tabular}{|c|c|}
\hline Gene & Primer sequence $\left(5^{\prime} \rightarrow 3^{\prime}\right)$ \\
\hline \multicolumn{2}{|l|}{ RACE } \\
\hline \multicolumn{2}{|l|}{ hsp19.5 } \\
\hline 5 & TTGGCAGAAGGTAACGGCGGGTGA \\
\hline 3 ' & CCAGTCACCAAAACCAACGCCCCA \\
\hline \multicolumn{2}{|l|}{ hsp19.2 } \\
\hline 5 & CGTTCTTCGTGTTTGGCGTGGAT \\
\hline 3 ' & CCCGCAATCAAACAGGAACAAGC \\
\hline \multicolumn{2}{|l|}{ hsp21.3 } \\
\hline 5 , & CTTCCAACAAGTAGGGCAAGAGAGAC \\
\hline 3 ' & AACCAATGCTCCCGCAATCAAACAGG \\
\hline \multicolumn{2}{|c|}{ Real time PCR } \\
\hline \multirow[t]{2}{*}{ hsp19.5 } & TGAGGAGCGTAGTGATGAAC \\
\hline & CCTTATCGTTGGTGATTGCC \\
\hline \multirow[t]{2}{*}{ hsp19.2 } & GCCAAACACGAAGAACGCAG \\
\hline & CTTGAAGTCAAGGCTTCCGC \\
\hline \multirow[t]{2}{*}{ hsp21.3 } & GCCAAACACGAAGAACGCAG \\
\hline & CAAGGCTTCCGCATTGACGT \\
\hline \multirow[t]{2}{*}{$E F-1 \alpha$} & TAGCCTTGTGCCAATTTCCG \\
\hline & CCTTCAGCATTACCGTCC \\
\hline
\end{tabular}




\section{Table 2 (on next page)}

Inferred amino acid sequence identities of sHSPs from Bemisia tabaci with its homologs from other insects. 
1 TABLE 2 Inferred amino acid sequence identities of sHSPs from Bemisia tabaci with its 2 homologs from other insects.

3

\begin{tabular}{|c|c|c|c|}
\hline NO. & Species & Name & Accession number \\
\hline 1 & Bemisia tabaci & Bthsp19.5 & AVL92582.1 \\
\hline 2 & & Bthsp19.2 & AVL92583.1 \\
\hline 3 & & Bthsp21.3 & AVL92584.1 \\
\hline 4 & & Bthsp20 B & ACH85196.1 \\
\hline 5 & & Bthsp20 Q & ADG03464.1 \\
\hline 6 & & Bthsp20 ZHJ-1 & ADG03467.1 \\
\hline 7 & & Bthsp20 ZHJ-2 & ADO14472.1 \\
\hline 8 & Trialeurodes vaporariorum & Tvshsp & ACI15853.1 \\
\hline 9 & & Tvhsp20 & ACH85200.1 \\
\hline 10 & Lygus hesperus & Lhhsp21.9 & AFX84562.1 \\
\hline 11 & & Lhhsp21.4 & AFX84561.1 \\
\hline 12 & & Lhhsp21.5 & AFX84563.1 \\
\hline 13 & Liriomyza huidobrensis & Lhhsp20 & ABE57137.1 \\
\hline 14 & Musca domestica & Mdhsp20 & AHK23446.1 \\
\hline 15 & & Mdshsp & ADT92004.1 \\
\hline 16 & Agasicles hygrophila & Ahhsp21 & АHН25011.1 \\
\hline 17 & Spodoptera litura & Slhsp20 & ADK55523.1 \\
\hline 18 & & Slhsp19.7 & ADK55524.1 \\
\hline 19 & Bombyx mori & Bmhsp20.8 & AAG30944.1 \\
\hline
\end{tabular}




\begin{tabular}{|c|c|c|c|}
\hline 20 & & Bmhsp19.9 & BAD74195.1 \\
\hline 21 & & Bmhsp21.4 & BAD74197.1 \\
\hline 22 & Locusta migratoria & Lmhsp20.5 & ABC84492.1 \\
\hline 23 & & Lmhsp20.7 & ABC84494.1 \\
\hline 24 & Oxya chinensis & Ochsp20.4 & AJP36907.1 \\
\hline 25 & Laodelphax striatella & Lshsp20.1 & AYP00110.1 \\
\hline 26 & & Lshsp21.2 & AYP00111.1 \\
\hline 27 & & Lshsp22.0 & AYP00114.1 \\
\hline 28 & Chilo suppressalis & Cshsp19.7 & BAE94664.1 \\
\hline 29 & & Cshsp21.4 & AGC23338.1 \\
\hline 30 & & Cshsp19.8 & AGC23337.1 \\
\hline 31 & Schistocerca gregaria & Sghsp20.7 & AEV89760.1 \\
\hline 32 & Frankliniella occidentalis & Fohsp 28.5 & AFX84622.1 \\
\hline 33 & & Fohsp28.7 & AFX84621.1 \\
\hline
\end{tabular}

4 
Figure 1

Alignment of the deduced amino acid sequences.

Alignment of the deduced amino acid sequences of BtHSP19.2, BtHSP21.3, BtHSP19.5, BtHSP20, and TVHSP20. Abbreviations, Bt, Bemisia tabaci; Tv, Trialeurodes vaporariorum. 


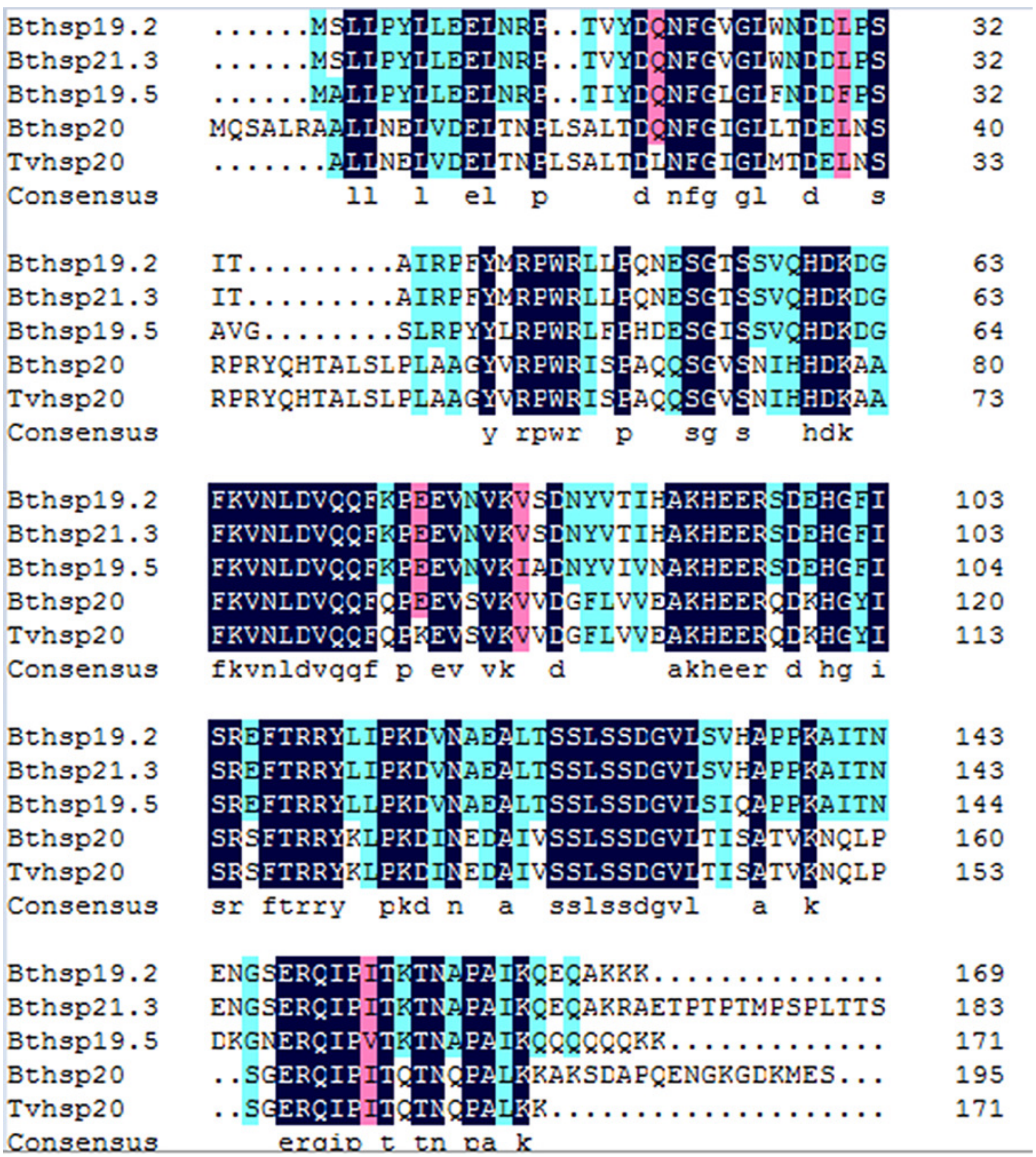


Figure 2

Neighbor-joining phylogenetic tree of selected insect sHSPs.

Neighbor-joining phylogenetic tree of selected insect sHSPs. Branches containing the Bemisia tabaci sHSPs identified in the present study are shaded. Numbers on the branches are bootstrap values obtained from 1,000 replicates (only bootstrap values $>50$ are shown). Accession numbers and abbreviations for the insect species are listed in Table 2. 


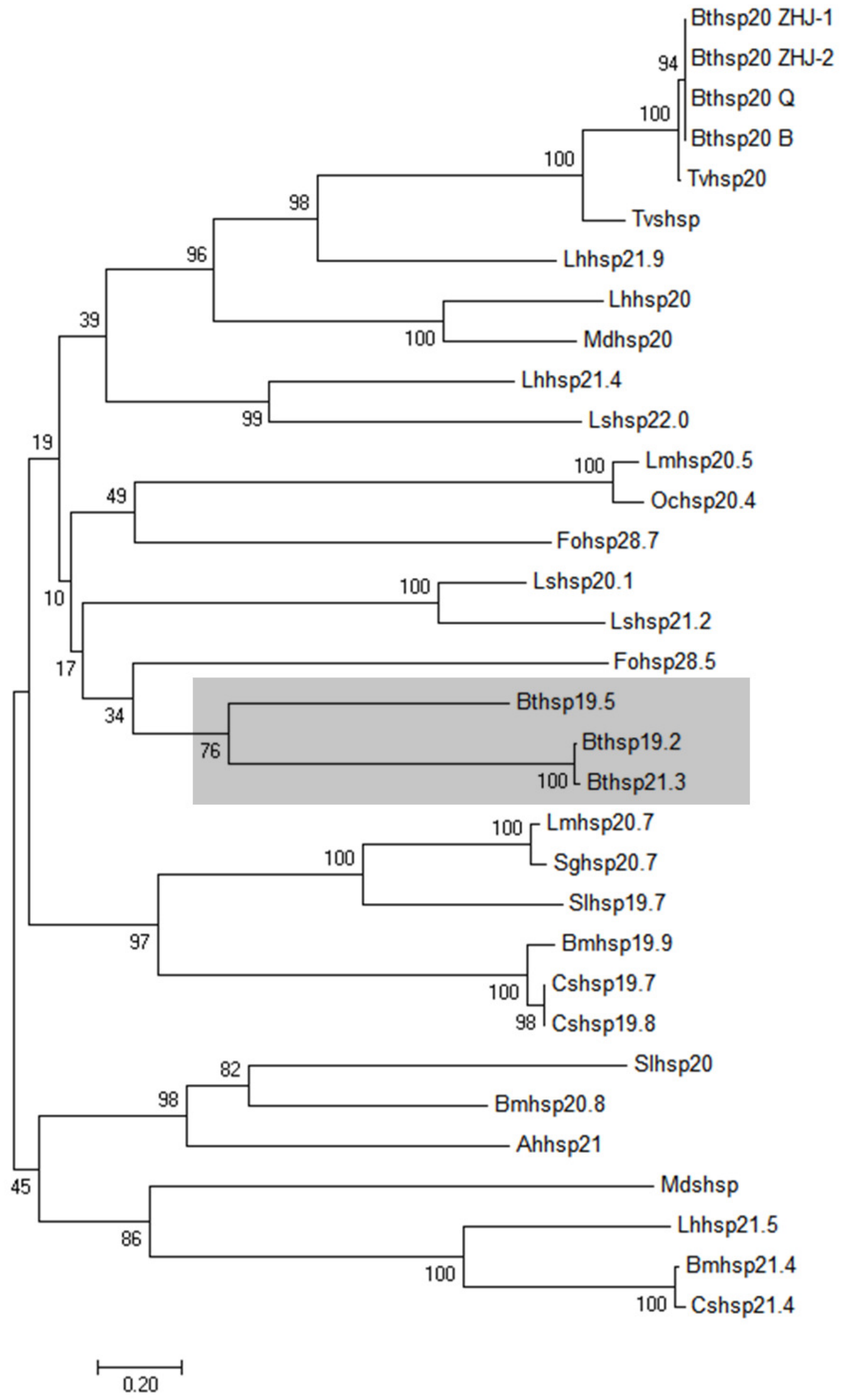




\section{Figure 3}

Schematic representation of shsps genomic structure in several insects.

Schematic representation of shsps genomic structure in several insects. Species names and accession numbers of genomic DNA sequences are as follows: Cshsp21.4 (Chilo suppressalis, JX491642); Bmhsp20.4 (Bombyx mori, AAG30945); Bmhsp21.4 (B. mori, BAD74197); and Lmhsp20.7 (Locusta migratoria, ABC84494.1). The first three lines represent genomic DNA from the three B. tabaci shsps identified in this study (Bthsp19.5, Bthsp19.2, and Bthsp21.3). Horizontal lines and black rectangles are used to demarcate exons and introns, respectively.

Bthsp 19.5

Bthsp19.2

Bthsp21.3

Cshsp 21.4

745

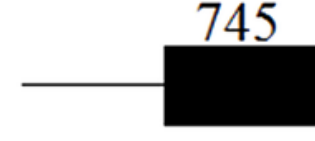

Bmhsp20.4

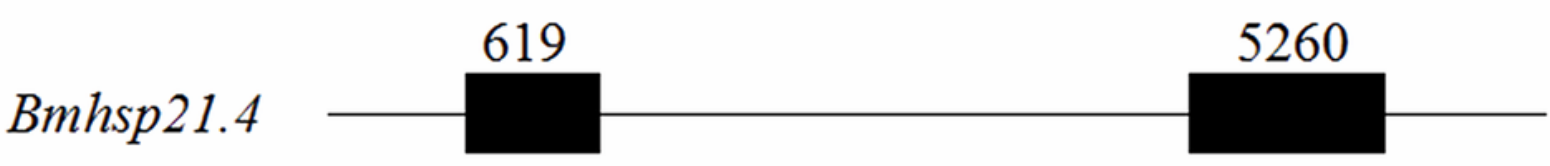

Lmhsp20.7 
Figure 4

Relative mRNA expression levels

Relative mRNA expression levels of Bthsp19.5, Bthsp19.2, and Bthsp21.3 in B. tabaci pupae and adults exposed to different temperatures. Relative expression levels are shown for Bthsp19.5, Bthsp19.2 and Bthsp21.3. Columns labeled with different letters represent significant differences at $P<0.05$. 


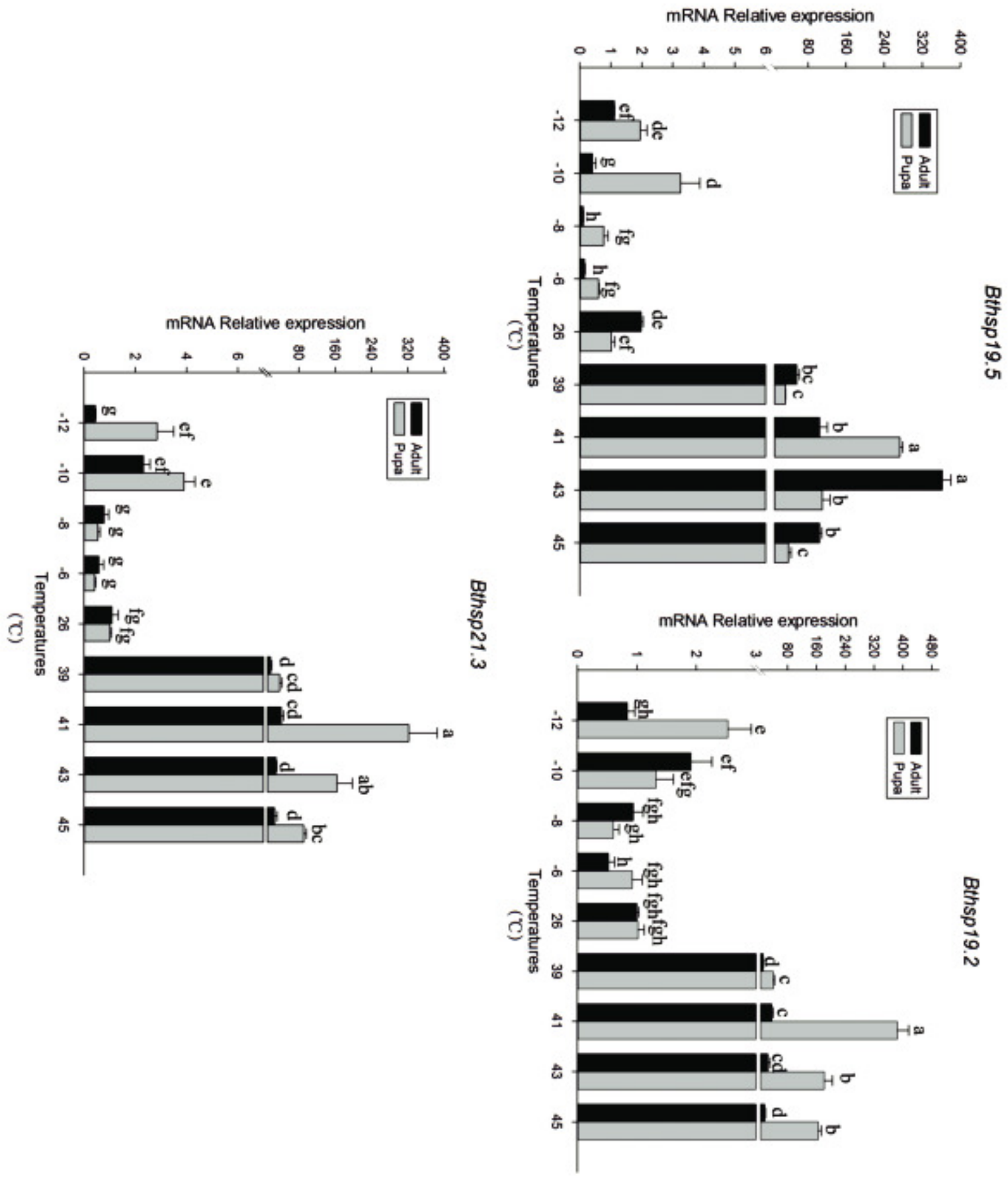

